\title{
Functional Synaptic Connections Made by Regenerated Retinal Ganglion Cell Axons in the Superior Colliculus of Adult Hamsters
}

\author{
Yves Sauvé, Hajime Sawai, and Michael Rasminsky \\ Centre for Research in Neuroscience, The Montreal General Hospital and McGill University, Montreal, Quebec, Canada, \\ H3G 1 A4
}

\begin{abstract}
Regenerated synaptic connections in the damaged mammalian visual system were studied in adult hamsters in which retinal ganglion cells (RGCs) regrew their axons through autologous peripheral nerve grafts directed from the stump of the transected optic nerve to the superior colliculus (SC). Unitary responses to illumination of small areas of the visual field were recorded within the superficial laminae of the reinnervated SC 23 to 60 weeks after grafting. Each element of a typical bursting response to light consisted of a terminal potential (TP) (half width $164 \pm 25 \mu \mathrm{sec}$, amplitude up to $171 \mu \mathrm{V}$ ) arising from a regenerated $\mathrm{RGC}$ axon terminal arborization, followed at a latency of $268 \pm 63 \mu \mathrm{sec}$ by a longer duration negative focal synaptic potential (FSP) (half width $938 \pm 396$ msec, amplitude up to $188 \mu \mathrm{V}$ ) reflecting EPSPs in neurons within the terminal field of the regenerated RGC axon. The FSP but not the TP was attenuated in a dosedependent manner by iontophoretic application of GABA. In some cases spikes arose from FSPs after the first two or three impulses of a train, presumably reflecting summation of EPSPs to threshold for excitation in SC neurons contacted by the regenerated RGC axon terminals. Up to one-third of the area of the SC can be infiltrated by arborizations of the regenerated $\mathrm{RGC}$ axons that enter the SC through a nerve graft inserted in the lateral aspect of the SC. These experiments indicate that terminal arborizations of individual regenerated RGC axons can synapse with multiple neurons in the SC and that convergence of inputs from regenerated RGC axons is not required for activation of SC neurons in response to light.
\end{abstract}

[Key words: electrophysiology, focal synaptic potential, GABA, regeneration, retinal ganglion cell, superior collicuIus, synapse, tectum, terminal potential]

Formation of functional synaptic connections in the mammalian CNS by retinal ganglion cell (RGC) axons has been demonstrated in experiments in which fetal rat retina was trans-

\footnotetext{
Received Sept. 23, 1993; revised May 5, 1994; accepted July 6, 1994.

We thank D. A. Carter and Y.-C. Wang for preparation of some of the grafted animals, Y. Fukuda for his participation in one of the early experiments reported here, and Janet Laganière for technical assistance. This work was supported by the Canadian Medical Research Council. Y.S. was the recipient of studentship awards from Fonds pour la formation de chercheurs et l'aide a la recherche (FCAR) and the Rick Hansen Man in Motion Legacy Fund. H.S. was recipient of a travel award from the Cell Science Research Foundation (Japan). The laboratory in which these studies were carried out is part of the Canadian Network for Neural Regeneration and Functional Recovery.

Correspondence should be addressed to Dr. Michael Rasminsky, Centre for Research in Neuroscience, Montreal General Hospital, 1650 Cedar Avenue, Montreal, Quebec, Canada H3G 1 A4.

Copyright (C) 1995 Society for Neuroscience $0270-6474 / 95 / 150665-11 \$ 05.00 / 0$
}

planted to the surface of the neonatal tectum (Simons and Lund, 1985), in experiments in which axotomized RGCs regenerated their axons through peripheral nerve grafts directed from the eye to the superior colliculus (SC) in adult hamsters (Keirstead et al., 1989), and in experiments in which explants of adult rat retina and fetal midbrain were placed side by side in vitro (Bähr and Eschweiler, 1991, 1992).

In all of these experimental situations, functional innervation of the tectum was established by the demonstration of excitation of postsynaptic neurons in response to electrical stimulation of the afferent RGC axons (Keirstead et al., 1989, Bähr and Eschweiler, 1991, 1992) or to diffuse illumination of the transplanted or in situ retina (Simons and Lund, 1985; Keirstead et al., 1989). Because these procedures would indiscriminately activate many RGCs or RGC axons, no assessment could be made of the extent of convergence of RGC inputs required to excite reinnervated tectal neurons. Furthermore, these experiments did not permit any assessment of the extent to which the input from individual RGC axons could diverge to influence the activity of multiple target neurons.

In the present study, we have recorded responses to light in the $S C$ reinnervated from the retina via a peripheral nerve graft using a method that permits: (1) discrimination of responses in postsynaptic neurons from responses in RGC axons; and (2) demonstration of both sub- and suprathreshold postsynaptic responses in $\mathrm{SC}$ neurons to inputs from single regenerated $\mathrm{RGC}$ axons. We find that individual regenerated $\mathrm{RGC}$ axons make excitatory synapses with several SC neurons, and that in some cases, input from a single RGC is sufficient to drive postsynaptic SC neurons to threshold for excitation.

These electrophysiological investigations of regeneration of retinocollicular connections via peripheral nerve grafts complement concomitant morphological studies that have demonstrated infiltration of the SC by regenerating $\mathrm{RGC}$ axons, formation of axonal terminal arbors, and establishment of synapses on neurons in the retinorecipient laminae of the SC (Vidal-Sanz et al., 1987, 1991; Carter et al., 1989, 1991a,b, 1994; Carter 1991).

\section{Materials and Methods}

Preparation of animals with peripheral nerve grafts. Peripheral nerve (PN) grafts linking the eye and the SC were prepared in 90-120-d-old female golden hamsters (Mesocricetus auratus) (weight 100-120 gm) as described by Carter et al. (1989). Under anesthesia with pentobarbital $(35 \mathrm{mg} / \mathrm{kg}$ i.p.), the optic nerve (ON) was transected at the sclera, taking care to preserve the ophthalmic artery, and a segment of autologous peroneal nerve $2-2.5 \mathrm{~cm}$ in length excised from the contralateral leg was sutured to the stump of the cut $\mathrm{ON}$. Immediately following anastomosis of the PN graft to the eye, the retina of the grafted eye was observed and animals with ischemic retinas were discarded. The nerve graft rested on the dura along a groove made in the skull, extending 
from the orbit towards the ipsilateral or contralateral occipital cortex In some cases, the graft was inserted into the $\mathrm{SC}$ at the same sitting; in other cases, the animals were reanesthetized 5 to 7 weeks later for insertion of the graft into the SC at a time when RGC axons would have been expected to have regenerated to the distal end of the graft (Vidal-Sanz et al., 1987). The most lateral part of the SC was exposed by suction of the overlying occipital cortex, taking care to leave most of the surface of the SC covered by cortex in order to assure easy penetration of the SC by recording electrodes in the subsequent physiological experiments. The distal end of the PN graft, sometimes divided into two to three branches, was inserted with a fine glass probe or a 30 gauge needle into the lateral aspect of the superficial SC, and was directed medially, parallel to the surface of the SC for about $0.5 \mathrm{~mm}$. In the subsequent physiological experiments, we noted no obvious differences among recordings made from the $\mathrm{S} C$. reinnervated by $\mathrm{RGC}$ axons regenerated from the ipsilateral or contralateral eye. We also noted no obvious differences in functional reinnervation between animals prepared with one stage grafting or those in which insertion of the graft into the $\mathrm{SC}$ was delayed for several weeks after replacement of the $\mathrm{ON}$ by the nerve graft.

To assess the success of the grafting procedure, the graft was exposed 15-35 weeks after grafting in seven animals, and $30 \%$ wheat germ agglutinin horseradish peroxidase (WGA-HRP) diluted in $0.9 \% \mathrm{NaCl}$ with $1 \%$ dimethylsulfoxide was applied to the freshly transected graft $2 \mathrm{~cm}$ from the eye to retrogradely label RGCs with regenerated axons (VidalSanz et al., 1987). Two days later, the animals were perfused with $0.9 \%$ $\mathrm{NaCl}$ followed by $4 \%$ paraformaldehyde in $0.1 \mathrm{M}$ phosphate buffer. The retinas were removed, whole mounted, and reacted for the presence of HRP (Hanker et al., 1977) as described by Vidal-Sanz et al. (1987). The average total number of HRP labeled cells per retina was $304 \pm 54$ (SD) (range 243 to 384 ).

Preparation of animals for physiological experiments. Physiological experiments were performed on a total of 46 grafted animals. We report here the results of successful experiments on 23 animals. Twenty-three to 60 weeks after the initial nerve graft, animals were anesthetized with urethane $25 \%$ (1.25 g/kg i.p.), which was supplemented as necessary throughout the experiment with additional doses of $0.25 \mathrm{~g} / \mathrm{kg}$ i.p. The trachea was cannulated and the animals were allowed to breathe spontaneously. The intact eye was enucleated to ensure that any visual responses recorded in the reinnervated $\mathrm{SC}$ would be mediated by regenerated RGC axons. The SC on the side of insertion of the nerve graft was exposed by careful aspiration of the overlying occipital cortex. Brain pulsations were minimized by incising the dura overlying the medulla. The animal's temperature was maintained at $37^{\circ} \mathrm{C}$ throughout the experiment by a thermoregulated heating blanket.

The animal was immobilized in the animal frame by a nose bar that left its visual field almost entirely unobstructed. This provided satisfactory stability for extracellular recording. The grafted eye was immobilized by three $6-0$ sutures in the conjunctiva attached to the animal frame. Pupillary dilatation that persisted for the duration of the experiment was obtained by application of $0.06 \%$ topical atropine, and a noncorrective contact lens was placed on the grafted eye to avoid dehydration of the cornea. The exposed SC was covered with mineral oil.

Nine intact female hamsters weighing 100-120 gm were prepared for terminal physiological experiments by aspiration of the occipital cortex overlying one side of the SC and enucleation of the ipsilateral eye. All procedures were otherwise the same as in the grafted animals.

Recordings. Extracellular recordings were made with a glass-insulated carbon fiber electrode (Keirstead et al., 1989) coupled to two glass micropipettes for iontophoretic injection. The carbon fiber in the recording electrode was electrolytically etched with $2 \mathrm{M} \mathrm{KNO}_{3}$ to a tapered point extending 14-18 $\mu \mathrm{m}$ from the end of the glass capillary filled with $3 \mathrm{M}$ $\mathrm{NaCl}$. The other pipettes were filled with $\gamma$-aminobutyric acid (GABA) (100 mm, pH 6.8, Sigma) and $\mathrm{NaCl} 3 \mathrm{~m}$ or $\mathrm{Na}$ glutamate $(100 \mathrm{~mm}, \mathrm{pH}$ 7.5, American Chemicals). The resistance of these two latter micropipettes ranged from 5 to $40 \mathrm{M} \Omega$. The $\mathrm{NaCl}$ electrode was occasionally used for a current control to verify that GABA effects were not due to passage of current. Iontophoresis of glutamate was used to elicit spontaneous discharges in order to establish the presence of viable neurons in the silent areas of the SC that were frequently encountered in these experiments.

Recordings were made with a band pass of $10 \mathrm{~Hz}$ to $5 \mathrm{kHz}$ unless otherwise noted in the figure legends. A $60 \mathrm{~Hz}$ notch filter was sometimes introduced but caused no significant distortions in the potentials of interest. Negative polarity is represented as downwards in all recordings.
The output of the recording amplifier was led to an audio monitor. Responses were stored on magnetic tape for subsequent off-line analysis. The analog recordings were digitized with a CED 1401 unit (Cambridge Electronic Design), usually at a digitization rate of $25 \mu \mathrm{sec} / \mathrm{bin}$, and further processed with CED software.

Location of visually responsive units. The recording electrode, held in a 3-D hydraulic micromanipulator, was initially placed about $200 \mu \mathrm{m}$ medial to the estimated site of insertion of the PN graft in the SC. A Grass photic stimulator was placed $10 \mathrm{~cm}$ in front of the grafted eye, and repeated penetrations to a depth of about $500 \mu \mathrm{m}$ below the surface of the SC were made at sites separated by $100-200 \mu \mathrm{m}$ until a response to flash was obtained (Keirstead et al., 1989). A translucent tangent screen, subtending approximately $120^{\circ}$, was then positioned $20 \mathrm{~cm}$ from the eye orthogonal to the projection of the optic disc as visualized by an ophthalmoscope. Units responsive to stimulation of a restricted visual receptive field (RF) were sought by projecting spots of light on the screen, and RFs were defined for individual units using the audio monitor. Responses to static and moving spots comparable to the RF size were tested for individual units before, during, and after iontophoretic application of GABA in order to distinguish presynaptic responses in $\mathrm{RGC}$ axons from postsynaptic responses in neurons.

Histology. At the conclusion of the experiment, a deep level of anesthesia was verified and the animal was killed by perfusion with $0.9 \%$ $\mathrm{NaCl}$ followed by $4.0 \%$ paraformaldehyde in $0.1 \mathrm{M}$ phosphate buffer. The brain was removed and stored in the same solution for at least 2 $\mathrm{d}$ before being cut in coronal section and stained with cresyl violet and Luxol fast blue to verify the position of the graft tip.

\section{Results}

\section{Unitary responses to light in the reinnervated SC of grafted animals}

We recorded 250 units with responses to illumination of defined visual fields. These units were found at a depth of no more than $420 \mu \mathrm{m}$ from the surface of the SC, as defined by the excursion of the micromanipulator after contact was made with the surface. This is within the boundaries of the retinorecipient superficial laminae of the SC (Chalupa, 1984, Mooney et al., 1985). Although spontaneously active units were frequently recorded more than $420 \mu \mathrm{m}$ below the surface, these were never responsive to light.

Visual RFs of individual units ranged from 4 to $10^{\circ}$ in diameter. We did not find units with clear directional sensitivity. Eighty-nine units responded to the onset of light (ON responses), 138 units responded to the offset of light (OFF responses), 17 units responded to both the onset and offset of light (ON-OFF responses), and 6 units responded inconsistently to visual stimuli.

\section{Pre- and postsynaptic components of the unitary responses}

A typical response to static illumination of a spot approximately $4^{\circ}$ in diameter is illustrated in Figure 1. The offset of light elicits a burst of impulses with initial frequency $\approx 200 \mathrm{~Hz}$. Each element of the burst consists of an initial narrow negative spike followed by a second wider negative deflection (Fig. 2). Iontophoretic application of GABA reversibly eliminates the second component without having any effect on the initial spike. This suggests that the initial GABA-insensitive component of the response is presynaptic and that the latter component is postsynaptic. The use of iontophoresis of GABA as a device to distinguish pre- from postsynaptic responses implies no judgment as to the site of action of GABA. Iontophoretically applied GABA could attenuate or eliminate postsynaptic responses either by a direct postsynaptic effect, or by a presynaptic effect on excitatory transmitter release (Nicoll and Alger, 1979). If a presynaptic effect of GABA were to attenuate or prevent propagation of impulses into nerve terminals (Zhang and Jackson, 


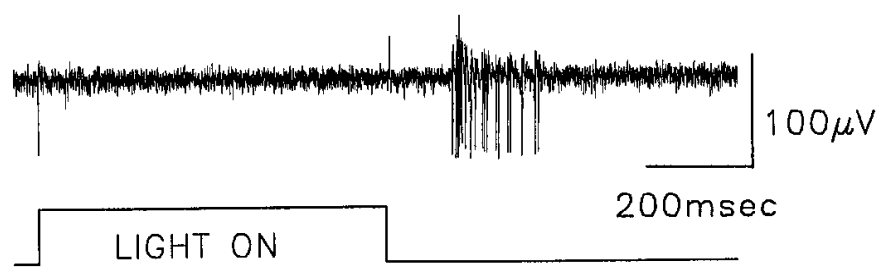

Figure 1. Unitary response to static illumination of a spot $4^{\circ}$ in diameter recorded at a depth of $190 \mu \mathrm{m}$ in a reinnervated SC 37 weeks after graft insertion. Bandpass $100 \mathrm{~Hz}$ to $5 \mathrm{kHz}$.

1993), a change would be expected in the configuration of the initial spike. Such changes were not observed.

During the initial part of the burst there was usually a transient increase in amplitude of the postsynaptic component with successive responses (Figs. 2, 3), suggesting synaptic facilitation similar to that seen at the neuromuscular junction (Hubbard, 1963; Mallart and Martin, 1967).

These records are similar in configuration to those that have been obtained from the frog tectum (Witpaard and ter Keurs, 1975 ) and from various other areas in the nervous system where spike-triggered averaging has been used to reveal the much smaller electrical potentials generated by a single afferent axon and a population of target neurons within its terminal field (Appenteng et al., 1978, 1989; Taylor et al., 1978; Munson and Sypert 1979; Berger and Averill, 1983; Dick et al., 1988; Iwamoto et al., 1990; Kirkwood et al., 1991, 1993; Schmid et al., 1993). Responses recorded in this way characteristically consist of a short duration triphasic or biphasic mainly negative terminal potential (TP) interpreted as the discharge of an afferent axon or its terminal arborization, which is sometimes followed at a short latency by a longer duration focal synaptic potential (FSP) representing an extracellular reflection of the postsynaptic potentials elicited by monosynaptic connections of the afferent axon with target neurons.

We take the presynaptic component of our records to represent the discharge in a single RGC axon terminal because of (1) its unchanged amplitude and configuration throughout the burst; and (2) its brisk repetitive response similar to that recorded from RGCs in intact rodents (Brown and Rojas, 1965; Partridge and Brown, 1970; Mooncy and Rhoades, 1990) and from regenerated axons of rodent RGCs (Keirstead et al., 1985, 1989). It is unlikely that the presynaptic recordings are from RGC axons recorded en passant distant from the terminal arborization. In repeated attempts we have found that the carbon fiber recording electrodes used in these experiments do not record unitary responses in either the graft itself or in the brachium of the SC of intact animals.

We obtained further support for our interpretation of the individual elements of unitary bursts as TPs followed by FSPs by examining averaged records. Because the amplitude of the second component or FSP varied within a burst, ideal averaging would not have been achieved by indiscriminately using the invariant TP as a trigger to average all of the events within several bursts. For this reason, we averaged multiple single sweeps off line with reference to the peak of the second or third TP within each burst as the reference time marker (Fig. 4). Because the trigger was derived from the signal to be averaged, only recordings with an adequate signal to noise ratio could be used for averaging in this way.
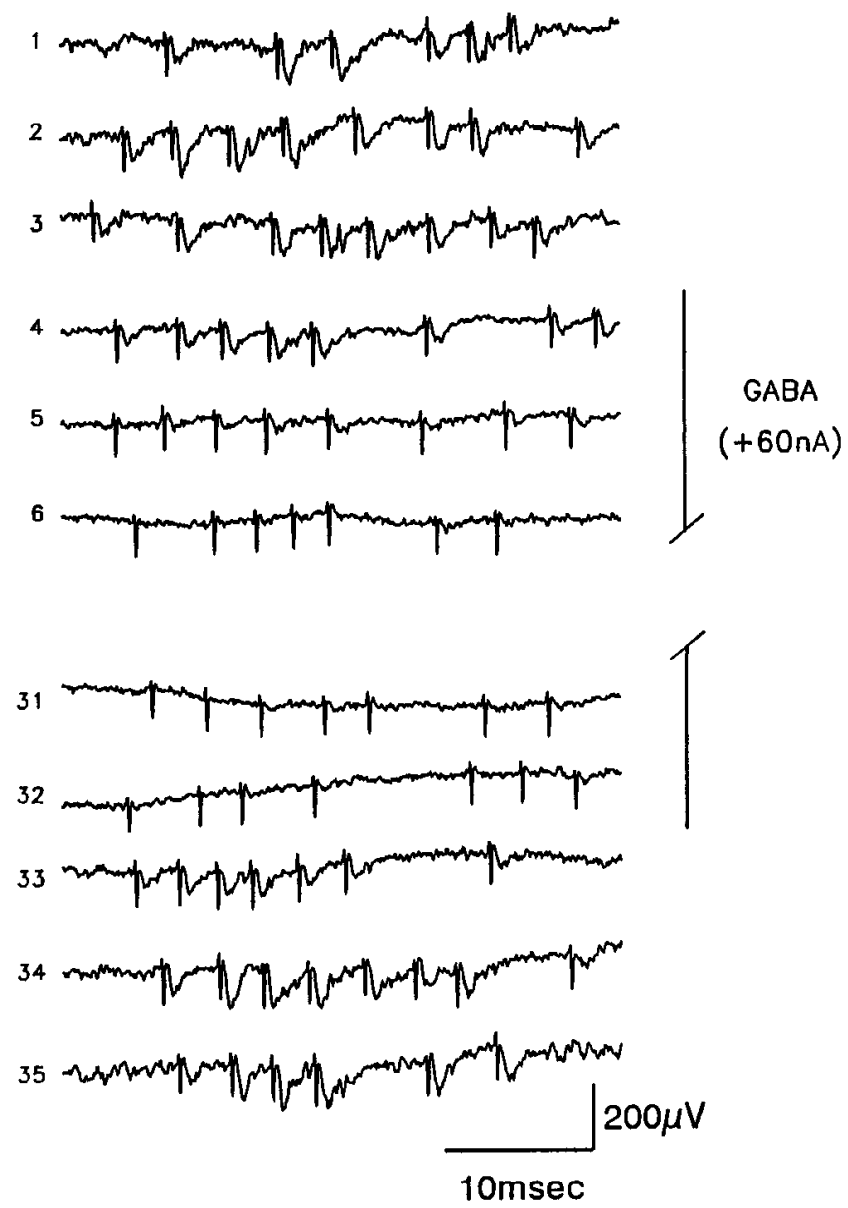

Figure 2. Successive OFF responses to repetitive light stimuli every $3.1 \mathrm{sec}$ from the same unit as in Figure 1 . Traces begin $125 \mathrm{msec}$ after offset of light. Band pass $10 \mathrm{~Hz}$ to $5 \mathrm{kHz}$. Following application of GABA between trace 3 and 4 , the second component of each unitary response is attenuated (traces 4 and 5) and then disappears on subsequent traces. When GABA application is discontinued after approximately $90 \mathrm{sec}$, the second component of each unitary response gradually recovers, becoming larger between trace 33 and 34 . The gradual attenuation and recovery of the second component indicates that the effect of iontophoretic administration of GABA is not a current effect. Traces 7 to 30 , during which GABA was continuously applied, are omitted.

The amplitude of the FSP decreased in response to application of GABA in a continuously dose-dependent manner with no concomitant effect on the shape or amplitude of the TP (Fig. $4 C)$. That the decrease in amplitude of the averaged single fiber FSP was not due to intermittent transmission failure is apparent from Figure 2 in which FSPs, visualized in single sweeps, are secn to decrease in amplitude immediately after administration of GABA and to recover gradually after GABA administration was stopped.

In several cases it was possible to record from the same unit at multiple depths within a given electrode tract. Unitary bursts were elicited by repetitive transient illumination of the same spot on the screen as the recording electrode was vertically displaced in discrete steps. In the example illustrated in Figure 5A, the configurations of the TP and the FSP change independently, both being maximal approximately $200 \mu \mathrm{m}$ beneath the surface of the colliculus. Although the amplitude of the second component changes with depth, its polarity remains negative throughout the approximately $200 \mu \mathrm{m}$ over which it can be 
A
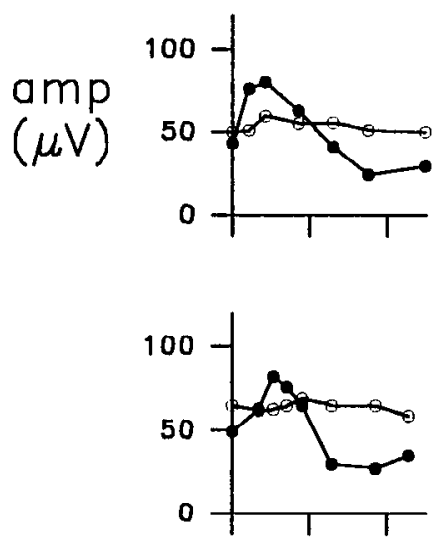

Amplitude of the initial presynaptic component (hollow circles) and of the subsequent postsynaptic component (filled circles) for successive responses during the first $45 \mathrm{msec}$ of bursts elicited by static illumination of a spot for four units from four different animals. $A$, OFF response, depth $110 \mu \mathrm{m}$; $B$, OFF response, depth $180 \mu \mathrm{m} ; C$, ON response, depth $100 \mu \mathrm{m} ; D$, ON response depth $400 \mu \mathrm{m}$. Three consecutive bursts elicited at an interval of 3.1 sec are illustrated for each unit. Time 0 is the time of initiation of each burst. The amplitude of the presynaptic component remains stable while the amplitude of the postsynaptic component is transiently increased at the beginning of each burst.

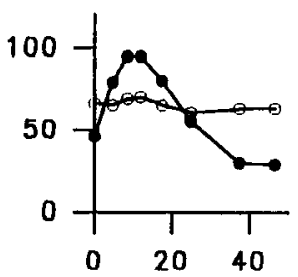

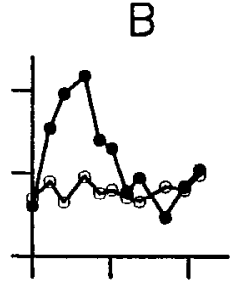
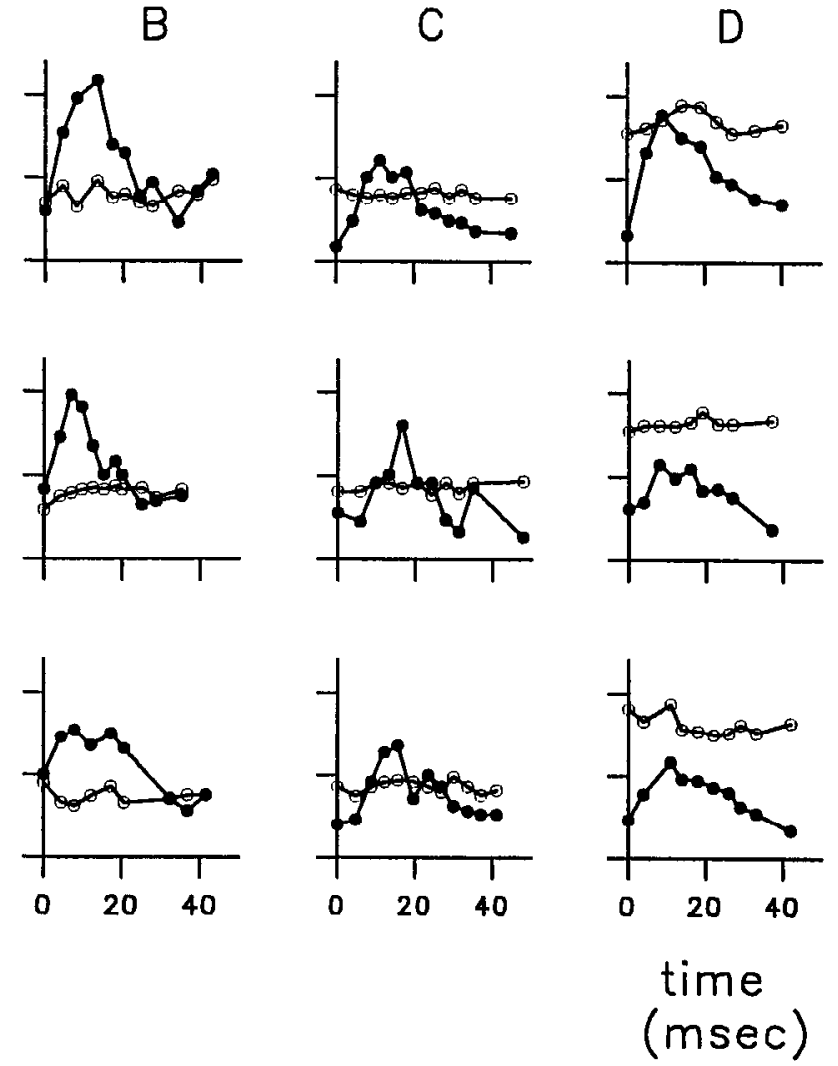

recorded. In Figure $5 B$, an FSP following the TP is not apparent in the most superficial five records spanning $100 \mu \mathrm{m}$, but is seen in the lower two records. Similarly, the FSP was sometimes seen to persist at levels where the TP could no longer be recorded (upper four records of Figure $5 A$ ). In Figure $5 A$ it appears that the terminal arborization giving rise to the TP lies beneath the region of the FSP within the superficial laminae of the SC, a TP without a subsequent FSP bcing apparent in the decper records. In contrast, in Figure $5 B$ the terminal arborization appears to lie above the region of the FSP. Regenerated RGC arbors projecting vertically both upwards and downwards have been seen within the superficial laminae of the $\mathrm{SC}$ in anatomical studies of similarly prepared animals (Carter, 1991).

The configurations of 43 visually responsive units with amplitudes large enough to permit reliable spike triggered averaging were studied in detail. For 33 units it was possible to identify both a TP and FSP. The narrow biphasic or triphasic TP had an average half width of $164 \pm 25$ (SD) $\mu$ sec and peak-to-peak amplitude ranging from just above the usual noise level of 20$30 \mu \mathrm{V}$ to a maximum of $171 \mu \mathrm{V}$ (Fig. $4 B$ ). The initial positive deflection of the TP was always much smaller than the subsequent major negative deflection. Latency to the FSP (measured as the time between the negative peak of the TP and the initial crossing of baseline of the negative defiection of the FSP-Fig. $4 B$ ) averaged $263 \pm 63$ (SD) $\mu \mathrm{sec}$ (range 175-400 $\mu \mathrm{sec}$ ), consistent with a monosynaptic delay.

The average half width of the negative FSP was $988 \pm 396$ (SD) $\mu$ sec. Measurement of the duration of the FSP was somewhat uncertain because of the difficulty of accurately identifying the return to baseline, a difficulty that was increased because of the displacement of the baseline due to the field potential described below. However this duration was invariably more than
$1 \mathrm{msec}$, ranging from 1.03 to $3.90 \mathrm{msec}$. The maximum FSP amplitude recorded was $188 \mu \mathrm{V}$. Sixteen out of 33 units had FSPs with amplitude greater than $80 \mu \mathrm{V}$. The depth beneath the surface at which the maximal FSP was recorded (as estimated from the excursion of the microelectrode from first contact with the surface) ranged from $0 \mu \mathrm{m}$ to $360 \mu \mathrm{m}$ with a median of $150 \mu \mathrm{m}$.

For nine units with well-defined RFs and amplitudes well above the noise level, a single GABA-resistant narrow spike was not followed by an obvious FSP. As is apparent from Figure 5, this did not necessarily mean that the presumed RGC axon spike was not associated with a postsynaptic component; a TP may be recorded alone less than $100 \mu \mathrm{m}$ from a site where the associated FSP becomes apparent. One unit was found at the surface of the $\mathrm{SC}$ in which a relatively wide unitary response with the configuration of an FSP occurred in the absence of an obvious TP. This resembled the upper traces of Figure $5 \mathrm{~A}$.

\section{Postsynaptic action potentials elicited by $R G C$ input}

Concomitant with the increase in amplitude of the FSP during the initial few responses of a burst, there was often an increase in baseline noise and spike-like activity superimposed on the falling phase of the FSPs as the burst continued (Figs. 4A,6). As for the FSPs, this spike-like activity was reversibly abolished by application of GABA. During long bursts, the increased baseline noise and spike-like activity superimposed on the FSPs was maximal after two or three closely spaced unitary responses, became less prominent as the interval between unitary responses became greater, and became more prominent again if the interval between unitary responses decreased in the latter part of a burst (Fig. 6A). 
A
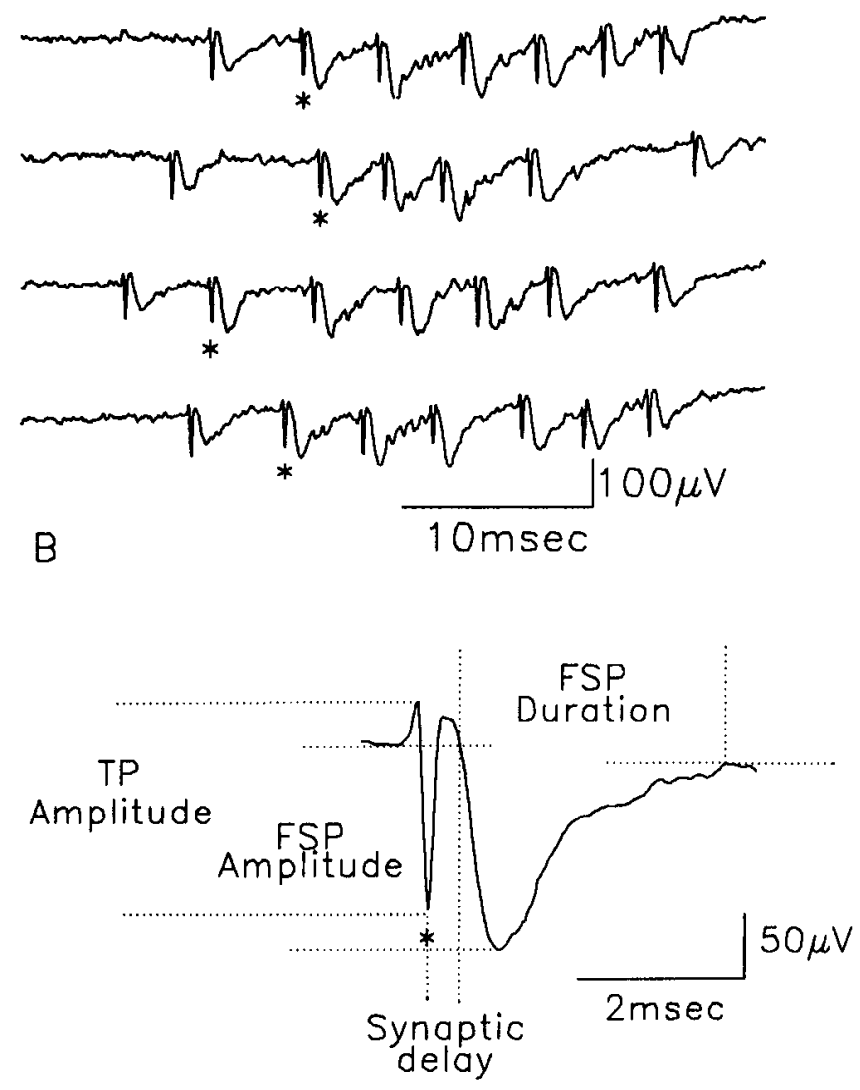

C

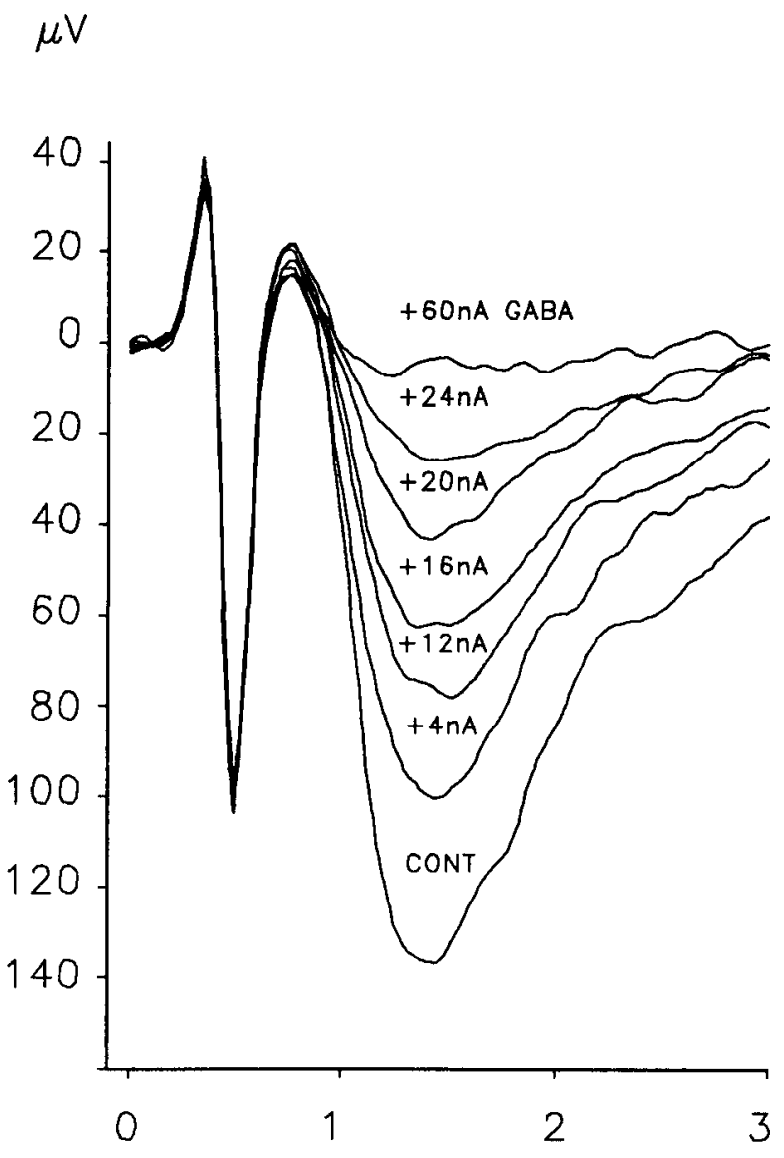

msec

Figure 4. $A$, Successive single sweeps in response to static illumination of a spot. Traces begin $125 \mathrm{msec}$ after offset of light. Depth $210 \mu \mathrm{m}$. $B$, Averaged records ( 29 sweeps in this example) are obtained off line by using the peak of the second TP in each single sweep (asterisks in $A$ and $B$ ) as the time reference. Amplitudes and durations of TPs and FSPs, and synaptic delays are measured from averaged records as shown. The baseline for the end of the FSP is displaced slightly downward because of a negative field potential (see Fig. 7). $C$, Changes in configuration of this unitary response with increasing doses of GABA. The FSP amplitude decreases continually in a dose-dependent manner but the TP is unaffected.

The spike-like activity superimposed on the FSP must represent firing of individual neurons (or possibly dendrites) that participate in generation of the FSP. For the most part, this activity is relatively small in amplitude, only slightly greater than the baseline noise. However, occasional responses were seen, as in Figure $6 B$, in which spikes with amplitude greater than $100 \mu \mathrm{V}$ arose from FSPs. The smaller amplitude spike-like activity presumably represents firing of dendrites or neurons relatively remote from the recording electrode, the larger spikes firing of neurons close to the electrode. Because individual spikes differ in amplitude and configuration, they must represent activity arising in different excitable structures. This is consistent with the possibility that a burst of activity in a single RGC can eventuate in activation of several postsynaptic neurons with which it makes synaptic connections. The timing of the spikelike activity, invariably beginning just after the crest of the FSP after two or three closely spaced RGC impulses in a burst, suggests temporal summation of EPSPs in postsynaptic neurons such that threshold for firing of individual neurons can be attained after two or three afferent impulses separated by less than
$10 \mathrm{msec}$. We did not record examples of discharges in postsynaptic neurons following TPs on a consistent 1:1 basis.

\section{Field potentials elicited by $R G C$ input}

When successive responses to static illumination were averaged with respect to the onset or offset of illumination, a small and persistent negative deflection from the baseline characteristically began in association with the bursting unitary response (Fig. 7). This negative slow wave was sometimes followed by a positive slow wave. When individual sweeps were averaged so as to bring the first spike in the burst into temporal alignment for each iteration (Fig. $7 C$ ), the onset of the slow wave or ficld potential was invariably found not to begin until immediately after the first spike in the spike train. This suggests that responses to other simultaneously activated axons did not contribute to the field potential, presumably because the exact time of onset of bursting in any other nearby axons would vary from iteration to iteration. This field potential could, thus, be entirely due to input from a single RGC axon. The amplitude of the initial negative component of this field potential ranged from 19 to 35 

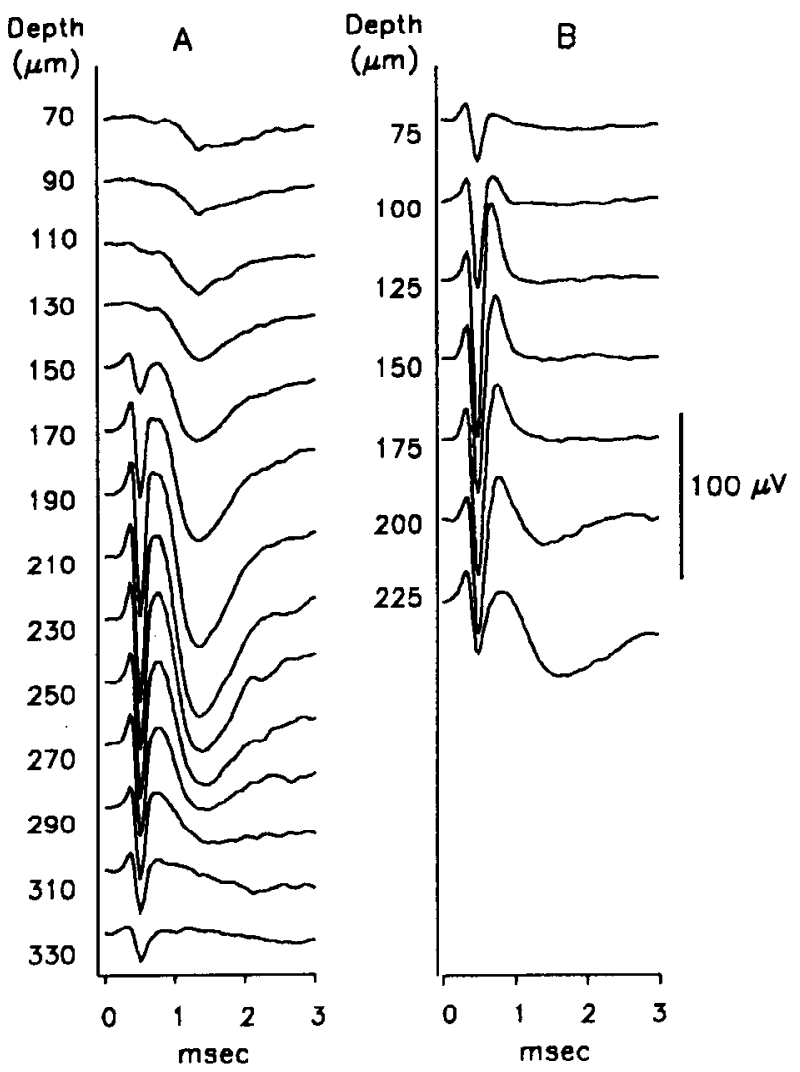

Figure 5. Averaged records (30 sweeps) obtained at successive depths for units from two different animals. Repetitive static illumination of a spot was maintained as the electrode position was changed. The averaged records represent the second response in each successive spike train obtained as in Figure $4 A$ and $B$. Successive responses are arbitrarily aligned in time with respect to the peak of the TP except for the top four records in $A$ that are aligned with respect to the peaks of their FSPs and the FSP in the record at depth $150 \mu \mathrm{m}$. $A$, Unit with an OFF response. $B$, unit with an $O N$ response.

$\mu \mathrm{V}$ and its duration ranged from 23 to $55 \mathrm{msec}(n=5)$. It was abolished by application of GABA.

\section{Extent of innervation of the $S C$}

Individual regenerated $\mathrm{RGC}$ axons innervating the $\mathrm{SC}$ were identified by virtue of their discrete receptive fields and response characteristics (i.e., ON, OFF, or ON-OFF). Brisk responses to illumination of apparently identical RFs were sometimes seen at recording sites separated by $150 \mu \mathrm{m}$ or less in the horizontal plane. We interpret such observations (52 cases in 17 animals) as probably representing adjacent recordings from the same terminal arbor which can extend for $150 \mu \mathrm{m}$ or more in the horizontal plane. Such adjacent recordings from the same terminal arbor are demonstrated more explicitly in successive recordings in the vertical plane (Fig. 5). The number of clearly distinguishable RGC axons recorded from the reinnervated SC of individual animals ranged from 4 to 63 , the largest number being recorded in an animal 60 weeks after a graft was directed from the eye to the contralateral SC in a single stage procedure. In this most extensively reinnervated animal, innervation extended for $1.2 \mathrm{~mm}$ in the mediolateral direction and $0.8 \mathrm{~mm}$ in the anteroposterior direction. The area within which responses could be recorded was approximately $0.95 \mathrm{~mm}^{2}$. For purposes of com-
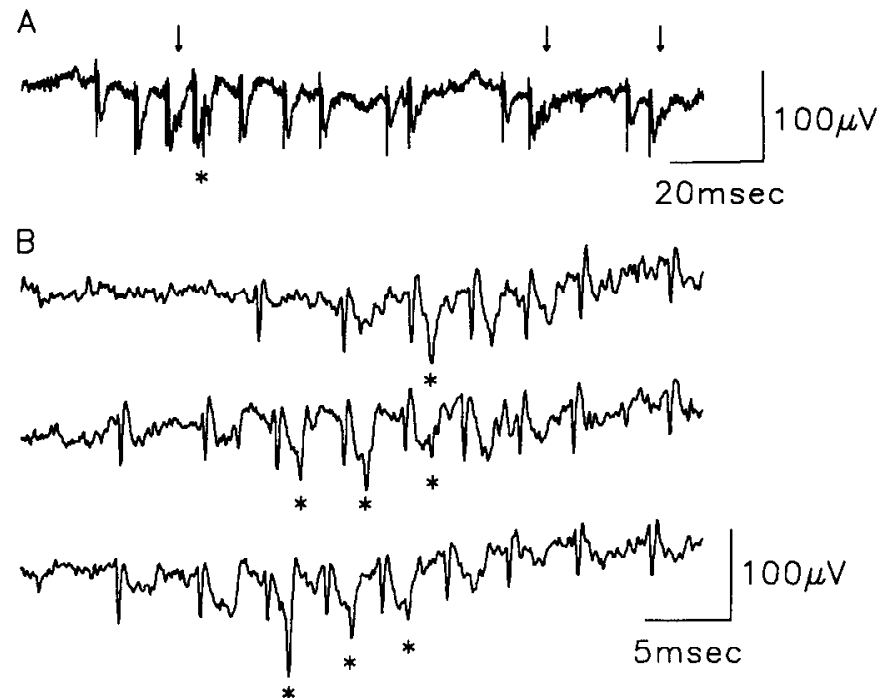

Figure 6. Spike-like activity arising from FSPs in single sweeps in response to static illumination of a spot. Recordings from units from two different animals. $A$, An OFF response. Depth $200 \mu \mathrm{m}$. Note increase in baseline noise after closely spaced impulses in RGCs (arrows) and spike-like responses that are not TPs (asterisk). $B$, Three ON responses with multiple associated spike-like responses (asterisks) arising from FSPs. Depth $100 \mu \mathrm{m}$.

parison we found in one intact hamster that the surface area of the SC within which we could find sites responsive to visual stimulation was approximately $2.6 \mathrm{~mm}^{2}$. It, thus, appears that the most extensive reinnervation of the SC that we observed covered approximately a third of the surface area of the SC.

At some recording sites where responses were found to diffuse flash, it proved impossible to demonstrate responses to illumination of visual RFs, despite careful systematic search of the entire visual field with projected spots of various sizes. Such responses to flash were frequently ill defined, and sometimes fatigued on repeated stimulation. They were more easily recognized by ear on the audio monitor than by eye on the oscilloscope screcn.

\section{Histology}

In all successful experiments on grafted animals, the position of the graft tip was found to be appropriately located no deeper than $400 \mu \mathrm{m}$ below the surface of the SC within the stratum griseum superficialis or the stratum opticum. In 9/23 animals in which no responses to visual stimulation could be found, the graft tip was found to be more than $600 \mu \mathrm{m}$ below the surface of the SC, and in a further five animals the graft tip was found to have become detached from the SC.

\section{Responses in the SC of intact animals}

The sparseness of innervation of the SC by regenerated RGC axons permitted positioning of the recording electrode so as to record discharges from the terminals of single RGC axons in response to illumination of a restricted visual $R F$. Identification of single units with carbon-fiber recording electrodes was much more difficult in the normally innervated $\mathrm{SC}$, where multiunit discharges were invariably recorded in response to illumination of restricted RFs. Individual elements within these discharges 
A

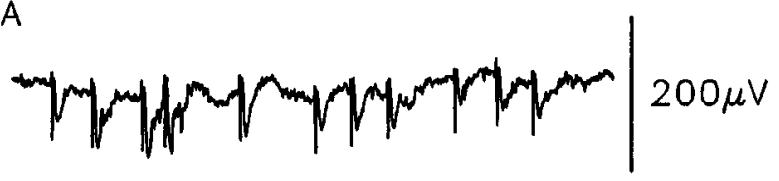

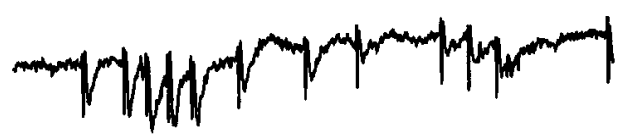

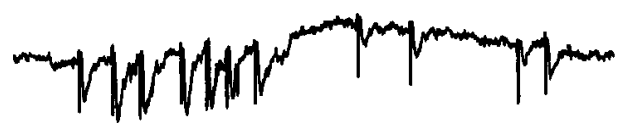

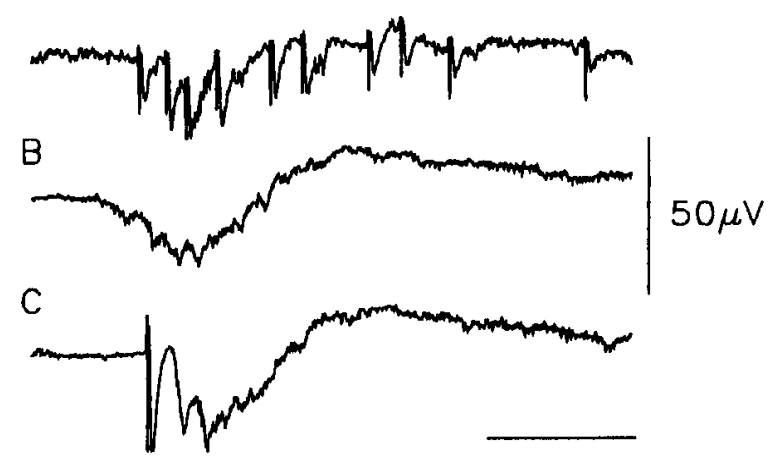

$20 \mathrm{msec}$

Figure 7. Field potentials in response to static illumination of a spot $4^{\circ}$ in diameter recorded at a depth of $210 \mu \mathrm{m}$ in a reinnervated SC. $A$, Single sweeps at intervals of $3.1 \mathrm{sec}$ beginning $130 \mathrm{msec}$ after the offset of light (bandpass $0.5 \mathrm{~Hz}$ to $5 \mathrm{kHz}$ ). $B$, Averaged records $(n=118$ ), each sweep beginning $130 \mathrm{msec}$ after onset of light as in $A$. C, Averaged records $(n=87)$ using the peak of the first TP in each burst as the time reference for averaging. The latter method of averaging indicates that the beginning of the field potential does not precede the first impulse in the spike train. $200 \mu \mathrm{V}$ voltage calibration for $A ; 50 \mu \mathrm{V}$ voltage calibration for $B$ and $C$.

were usually biphasic with an initial negative deflection, had half-widths of approximately $200 \mu \mathrm{sec}$, and were almost invariably abolished by iontophoretic application of GABA if their amplitude was larger than $20-30 \mu \mathrm{V}$; these were presumably spikes generated in postsynaptic neurons. The small spikes that persisted after application of GABA could have been TPs of RGC axonal arbors. The possible presence of FSPs as seen in the reinncrvated $\mathrm{SC}$ was almost invariably obscured by the multiunit activity. The onset of multiunit activity in response to static illumination of a restricted area of the visual field was associated with the onset of complex, initially negative field potentials that followed both the onset and offset of light (Fig. 8). These potentials, probably elicited by activation of several RGCs, were larger (amplitude $61-400 \mu \mathrm{V}$ ) and longer in duration (70-336 msec) than the similar field potentials elicited by single fiber inputs in the reinnervated colliculus.

In order to assess the response to single $\mathrm{RGC}$ afferents in intact animals, an attempt was made to reduce the number of RGCs afferent to the SC by making an intracranial lesion of the contralateral $\mathrm{ON}$ with a pair of ophthalmic scissors just anterior to the chiasm where there is minimal topological organization (Simon and O'Leary, 1991). A lesion at this point in the nerve would be expected to reduce the RGC input uniformly to all

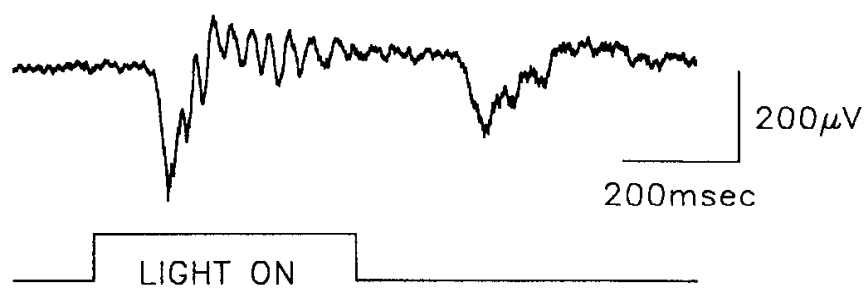

Figure 8. Field potentials (average of 25 sweeps at depth $50 \mu \mathrm{m}$ ) following both onset and offset of light in a normally innervated SC (bandpass $0.5 \mathrm{~Hz}$ to $5 \mathrm{kHz}$ ). The visual stimulus was a static spot $4^{\circ}$ in diameter delivered every $3.1 \mathrm{sec}$.

parts of the contralateral SC. Figure 9 illustrates the response to illumination of a restricted visual RF in such a partially denervated SC. The response is initiated by two potentials similar in amplitude and duration to FSPs elicited by the discharge of single regenerated RGC axons. The response then becomes more complex with superimposition of several FSP-like potentials and spike-like activity, presumably reflecting firing of other neighboring RGC axons and SC neurons. Application of GABA abolished all of the activity except for small narrow potentials at just above the level of the amplifier noise that were presumably TPs generated in normal RGC terminal arbors.

Because of the difficulty of uncquivocally identifying such nonspiking subthreshold responses as responses to single afferents, we were able to compile only a limited amount of data concerning the amplitude and duration of single fiber FSPs in intact animals. For five single fiber FSPs identified with reasonable certainty (as for the first two responses in the upper record of Fig. 9), the amplitude ranged from 43 to $76 \mu \mathrm{V}$, the duration ranged from 2.05 to $3.65 \mathrm{msec}$, and the average halfwidth was $1.46 \pm 0.25$ (SD) msec. These values are comparable to those found in the reinnervated animals.

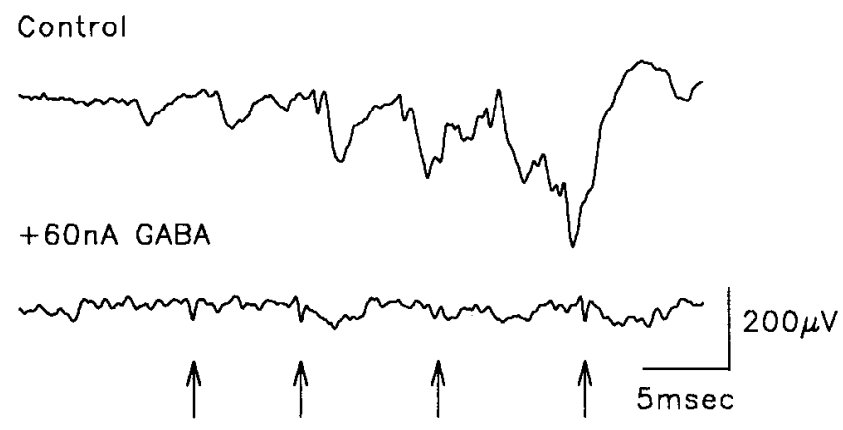

Figure 9. Response to static illumination of a spot $4^{\circ}$ in diameter recorded at a depth of $50 \mu \mathrm{m}$ in a partially denervated $\mathrm{SC}$ before and during administration of GABA. The onset of light precedes the sweep by $60 \mathrm{msec}$. The response (upper trace) is initiated by two potentials with the appearance of single fiber FSPs which, although not preceded by TPs, are presumably elicited by a discharge in a single RGC terminal as in the upper records of Figure $5 \mathrm{~A}$. These FSPs are followed by two larger FSP-like potentials each of which is associated with a preceding TP just above the noise level that persists during administration of GABA (arrows in lower trace). These TPs presumably arise from a second RGC axon terminal. The third and fourth FSPs in the upper trace may be composite FSPs generated by inpul from two or more RGC axon terminals, the burst in the second terminal beginning about $10 \mathrm{msec}$ after the burst in the first (the first two spikes of which elicited the first two FSPs in the trace). Towards the end of the trace, multiple pre- and postsynaptic responses overlap. 
The principal findings of these limited experiments on normally innervated colliculi were that (1) RGC TPs comparable in amplitude to those seen in the reinnervated SC were not observed; and (2) the amplitudes and durations of FSPs elicited by RGC axons in the normally innervated SC are comparable to those elicited in the reinnervated $S C$.

\section{Discussion}

These experiments have shown that the terminals of individual regenerated RGC axons synapse with neurons within the superficial retinorecipient layers of the $\mathrm{SC}$, in some cases with sufficient potency that the input from a single RGC can elicit spikes from cells that it contacts.

\section{Characteristics of pre- and postsynaptic potentials evoked by} single regenerated axons in the reinnervated $S C$

Terminal potentials. The potential recorded from an RGC terminal arbor presumably reflects simultaneous depolarization of many terminal branches that have a much larger surface area of cxcitablc membranc than docs the parent axon. During normal development, RGC axons innervating the hamster SC give rise to arbors with diameters of up to several hundred micrometers within the superficial laminae (Sachs and Schneider, 1984; Mooney and Rhoades, 1990; Carter, 1991). RGC axons regenerating in the SC are larger in diameter (average 1.5-2.5 $\mu \mathrm{m}$ ) than those of normal RGC axons within the SC (average 0.7$0.9 \mu \mathrm{m}$ ), but regenerated terminal arbors are more constricted and denser than those of normal axons (Carter et al., 1991b, Carter, 1991). Although the extent of terminal arbors is reduced in both anteroposterior and dorsoventral planes, the total number of synaptic boutons per arbor is as great in some regenerated arbors as in normal arbors, and the bouton density per unit volume is increased more than 10 -fold within terminal arbors of regenerated axons (Carter, 1991; Carter et al. 1991b). The much larger amplitude of TPs recorded from regenerated RGC axon terminals (up to $171 \mu \mathrm{V}$ ) in comparison to those recorded from intact axon terminals (which were seldom above the noise level of 20-30 $\mu \mathrm{V}$ ) may, thus, reflect both the larger diameter of the parent axon and a particularly large surface area of excitable membrane per unit volume, some of which is contributed by the terminal boutons. TPs with amplitudes larger than the noise level were recorded from regenerated single RGC fibers over vertical distances of up to $200 \mu \mathrm{m}$ (Fig. 5). This distance is consistent with the length of some terminal arbors visualized in the reinnervated SC (Carter, 1991). Adjacent penetrations separated horizontally by $150 \mu \mathrm{m}$ also sometimes appeared to record from the same RGC arbor.

Focal synaptic potentials. Because the FSP is graded in its response to administration of $\mathrm{GABA}$, it cannot represent an all or none discharge of a single cell. Could the FSP represent firing of a group of cells? The first FSP in a train of responses is invariably smaller than subsequent FSPs and would, thus, be less likely to conceal spike-like activity if such activity were contributing to the FSP. The appearance of spike-like activity arising from the FSPs after the first two or three impulses of a burst, but not after the first impulse, suggests that firing of neurons does not contribute significantly to the FSPs. We, thus, conclude that FSPs reflect primarily subthreshold postsynaptic potentials.

A negative single fiber FSP is thought to reflect inward flow of current across soma or dendrites of cells in the vicinity of the recording electrode (see Kirkwood et al., 1993, for review) and, thus, represents EPSPs in the neuron pool innervated by the afferent axon. For a number of reasons it is likely that FSPs elicited by activity in regenerated RGC axons represent an extracellular summation of currents generated by EPSPs in several SC neurons rather than a response in a single neuron: (1) the amplitude of the FSP, as great as $188 \mu \mathrm{V}$, is extraordinarily large for an extracellular, nonspiking response from a single neuron. FSPs of $50 \mu \mathrm{V}$ or less in the vicinity of the termination of Ia afferents to a homonymous motoneuron pool (Munson and Sypert, 1979) reflect an extracellular summation of currents generated by EPSPs of up to several hundred $\mu \mathrm{V}$ that can be successively recorded from individual cells among the large number of motoneurons contacted by the same afferent (Mendell and Henneman, 1971); (2) this response can be continually recorded as the position of the recording electrode changes by as much as $200 \mu \mathrm{m}$ (Fig. 5); (3) the polarity of the response remains negative at all recording sites, rather than changing, as would be expected if the recording electrode were moving with respect to sources and sinks of current in a single cell rather than a population of cells; (4) spikes with multiple configurations, presumably arising from several different structures, sometimes arose from the falling phase of successive FSPs within a single spike train (Fig. 6). We think it reasonable to conclude, on the basis of the evidence summarized above, that regenerated RGC axons functionally contact several SC neurons within their terminal field, although it must be acknowledged that definitive proof of this assertion would require sequential intracellular recording from multiple SC neurons. Our interpretation of the physiological recordings is consistent with the morphological finding that individual regenerated RGC axon terminals can make synapses with multiple dendrites that may belong to several SC neurons within their field of terminal innervation (Carter et al., 1989, 1994).

Spike generation. Generation of spikes after two or three impulses implies temporal summation to threshold of EPSPs, as has been observed for cells in the dLGN firing under the influence of single RGC inputs (Mastronarde, 1987). Such temporal summation would be expected to occur if the amplitude of the EPSPs were close to threshold and if the membrane time constant of the SC neurons excited by RGC axons were comparable to the interspike interval of the afferent input, i.e., as little as 5-6 msec at the beginning of some RGC bursts (see Figs. 2, 4, 6,7 ). How well does this correspond to the amplitude and lime course of the observed FSPs?

Although there is no experimental data available concerning the amplitude of single fiber EPSPs elicited by single RGC inputs, it is likely that the large amplitude of FSPs found in the reinnervated $\mathrm{SC}$ in response to excitation of individual RGCs bespeaks correspondingly large EPSPs in SC neurons. The average amplitude of single fiber FSPs elicited by Ia afferents in motor neurons is only $8 \mu \mathrm{V}$ (Collins et al., 1986), but the corresponding EPSPs may be as large as several hundred $\mu \mathrm{V}$ (Mendell and Henemann, 1971). If the amplitude of some single fiber EPSPs is correspondingly greater than that of the largest recorded FSPs, which we found to be close to $200 \mu \mathrm{V}$ in the reinnervated $\mathrm{SC}$, it is possible that individual fiber EPSPs in the reinnervated $S C$ would also substantially exceed $1 \mathrm{mV}$. EPSPs of amplitude $\approx 1 \mathrm{mV}$ elicited by single retinal afferents have been observed in retinorecipient neurons in the frog tectum (Nagano et al., 1988).

The inward membrane currents giving rise to negative FSPS presumably flow across the dendrites and dendritic spines of SC 
neurons that are the sites of synaptic input from both normal and regenerated RGC axons (Carter et al. 1991a, 1994). The extracellularly recorded FSP is not simply a mirror image of EPSPs within the terminal field of the afferent axon but may, in its time course, more precisely reflect the more rapidly changing membrane current. The durations of the putatively large EPSPs elicited by single RGC inputs in SC neurons may, thus, be considerably longer than the duration of up to $3.9 \mathrm{msec}$ found for FSPs in the reinnervated SC, certainly consistent with the tcmporal summation to threshold observed when interspike intervals fell to 5-6 msec.

\section{Nature and extent of reinnervation of the $S C$ by regenerating axons}

The strength of the regenerated synaptic contacts in the SC is reminiscent of the highly effective synapses between RGCs and their retinorecipient neurons in the mammalian dorsolateral geniculate nucleus (dLGN), where inputs from single cat RGC axons can give risc to firing in postsynaptic neurons (Bishop et al., 1962; Cleland et al., 1971; Mastronarde, 1987). Modelling studies suggest that dendritic inputs from single RGC axons can give rise to somatic EPSPs with amplitudes of several $\mathrm{mV}$ in relay neurons in the feline dLGN (Bloomfield and Sherman, 1989).

In the absence of intracellular recordings, it is not possible to compare the effectiveness of individual RGC inputs to SC neurons in the intact and reinnervated SC. In the reinnervated SC, RGC axon tcrminals synapse on dendrites and dendritic spines of SC neurons in the same proportions as in intact animals, and the ultrastructural properties of individual regenerated and normal retinocollicular synapses are strikingly similar except for some increase in length and area of the regenerated synapses (Carter et al., 1991a; 1994). However, comparisons have not been made between the number of RGC synapses investing SC neurons in intact animals and in animals with retinocollicular nerve grafts. Because constriction of the arbors of regenerated RGC axons is not accompanied by any reduction in the total number of synaptic boutons per arbor (Carter, 1991; Carter et al., $1991 \mathrm{~b}$ ), the same number of synapses per regenerated afferent axon may be distributed over a more limited number of retinorecipient neurons in the reinnervated $\mathrm{SC}$, thus enhancing the synaptic drive from individual RGCs on those SC neurons that are reinnervated. It is also possible that multiple synapses are selectively made on certain neurons within the terminal field, completely bypassing others, as is the case for the innervation of dLGN neurons by fcline RGC axons (Hamos ct al., 1987).

The responsiveness of $\mathrm{SC}$ neurons to input from regenerated RGCs is not necessarily the same as that of such neurons to direct RGC input in intact animals. Following ON section, all indirect visual inputs to $\mathrm{SC}$ neurons from multiple other areas such as lateral geniculate, visual cortex, and pretectal nuclei (Huerta and Harting, 1984) are permanently interrupted, and these inputs cannot modulate the responses of SC neurons to regenerated direct retinal input as in the intact animal (Chalupa, 1984). Furthermore, the observation that the RF sizc of SC neurons in intact animals can be dramatically and reversibly manipulated by the administration of amphetamine (Grasse et al., 1993) indicates that the efficacy of RGC inputs on SC neurons can vary over extremely wide limits.

The invariable localization of the TPs and FSPs to the superficial $420 \mu \mathrm{m}$ of the SC is in agreement with the morphological studies that have shown that regenerated RGC axons directed into the SC arborize and make synapses almost cxclusively within the superficial retinorecipient laminae (Carter et al. 1989, 1994; Carter, 1991). The distribution of FSPs elicited by regenerated RGC fibers from the most superficial to the deepest levels of the superficial laminae is similar to the distribution of visually responsive neurons in the intact SC (Tiao and Blakemore, 1976b; Finlay et al. 1978; Mooney and Rhoades, 1985) and indicates that neurons at all levels of the superficial $\mathrm{SC}$ can be activated by regenerated RGC axon terminals.

The few hundred RGCs that regenerated their axons into PN grafts (see Materials and Methods) represent only a very small proportion of the approximately $10^{5} \mathrm{RCCs}$ in the intact hamster retina (Tiao and Blakemore, 1976a). Nonetheless, the area reinnervated by the axons emerging from the tip of a nerve graft can extend for more than $1 \mathrm{~mm}$ in its largest dimension and may cover as much as one-third of the surface area of the SC. These electrophysiological findings are in agreement with morphological studies that show that regenerated RGC axons extend an average distance of more than $700 \mu \mathrm{m}$ from thc graft tip 46 months after its insertion into the SC (Carter et al., 1994). It appears that each regenerated axon makes synaptic contacts with many postsynaptic neurons, the overall sparseness of innervation being partly compensated by this synaptic divergence and by the efficacy of individual synapses in this retinofugal system. The number and proportion of neurons within the field of innervation that can be excited by visual stimulation may be substantially larger than the number and proportion of RGCs with regenerated axons.

\section{Functional implications}

The limited innervation of the midbrain by regenerating RGC axons in this experimental paradigm appears to be sufficient to subserve simple visual behavioral responses. Pupillary responses to light are mediated by $\mathrm{PN}$ grafts directed from the eye to the olivary pretectal nucleus in the rat (Thanos, 1992), and hamsters with similar grafts directed from the eye to the ipsilateral SC develop light avoidance bchavior in a conditioned-avoidance response paradigm (Sasaki et al., 1993). These findings are similar to those in experiments in which fetal retinae transplanted to the brains of neonatal rats innervate various retinorecipient nuclei in the brainstem (Lund et al., 1991). Illumination of such retinal transplants can drive the pupillary light response (Klassen and Lund, 1987, 1990) and can elicit a conditioned suppression response in a Pavlovian conditioning paradigm (Coffey et al., 1989).

Behavioral responses to light in these experimental paradigms imply transmission of information forward within the nervous system beyond the tectal neurons contacted by regenerated RGC axons. Because such neurons can, as we have shown, be excited by inputs from single RGCs, integration of multiple regenerated inputs at the level of the retinorecipient cell is not a requirement for onward transmission of information. Furthermore, because it appears that single regenerated RGC axons can effectively contact multiple SC neurons, a restricted number of $\mathrm{RGCs}$ with regenerated axons may be capable of driving a much larger number of neurons in the CNS with ensuing behavioral consequences.

To what extent are our findings relevant to the possibility of reconstruction of behaviorally functional circuitry in other pathways in the CNS? A unique feature of the visual system is the possibility of transmission of information on the basis of $1: 1$ transmission from RGC axons to retinorecipient neurons. This 
may be an important component of the capacity of the visual system for functional regeneration. Most excitatory synapses in the mammalian CNS give rise to EPSPs that are in the range of tens or exceptionally hundreds of $\mu \mathrm{V}$. Onward transmission of information from most cells in the CNS, even unmodified by the subtleties of synaptic modulation, ordinarily demands integration of multiple inputs in order to reach threshold for firing. For most pathways in the mammalian $\mathrm{CNS}$, the requirements for recreation of functional circuitry may be much more exigent than those in the retinofugal system, demanding not only reformation of individual synapses with properties resembling those in the intact animal, but integration of many such synapses to allow both temporal and spatial summation of regenerated inputs.

\section{References}

Appenteng K, O'Donovan MJ, Somjen G, Stephens JA, Taylor A (1978) The projection of jaw elevator muscle spindle afferents to fifth nerve motoneurones in the cat. J Physiol (Lond) 279:409-423.

Appenteng K, Conyers L, Moore JA (1989) The monosynaptic excitatory connections of single trigeminal interneurones to the $\mathrm{V}$ motor nucleus of the rat. J Physiol (Lond) 417:91-104.

Bähr M, Eschweiler GW (1991) Regenerating adult rat retinal axons reconnect with target neurons in vitro. Neuroreport 2:581-584.

Bähr M, Eschweiler GW (1992) Formation of functional synapses by regenerating adult rat retinal ganglion cell axons in midbrain target regions in vitro. $\mathrm{J}$ Neurobiol 24:456-473.

Berger AJ, Averill DB (1983) Projection of single pulmonary stretch receptors to solitary tract region. J Neurophysiol 49:819-830.

Bishop PO, Burke W, Davis R (1962) The interpretation of the extracellular response of single lateral geniculate cells. J Physiol (Lond) $162: 451-472$.

Bloomfield SA, Sherman SM (1989) Dendritic current flow in relay cells and interneurons of the cat's lateral geniculate nucleus. Proc Natl Acad Sci USA 86:3911-3914.

Brown JE, Rojas JA (1965) Rat retinal ganglion cells: receptive field organization and maintained activity. J Neurophysiol 28:1073-1090.

Carter DA (1991) Differentiation of regenerated retinal ganglion cell connections in the superior colliculus of adult hamsters. Ph.D. thesis, McGill University

Carter DA, Bray GM, Aguayo AJ (1989) Regenerated retinal ganglion cell axons can form well-differentiated synapses in the superior colliculus of adult hamsters. J Neurosci 9:4042-4050.

Carter DA, Aguayo AJ, Bray GM (1991a) Retinal ganglion cell terminals in the hamster superior colliculus: an ultrastructural study. J Comp Neurol 311:97-107.

Carter DA, Bray GM, Aguayo AJ (1991b) Patterns of the arborization made by retinal ganglion cell axons regenerating into the superior colliculus of adult hamsters. Soc Neurosci Abstr 17:568.

Carter DA, Bray GM, Aguayo AJ (1994) Long-term growth and remodelling of regenerated retino-collicular connections in adult hamsters. J Neurosci 14:590-598.

Chalupa LM (1984) Visual physiology of the mammalian superior colliculus. In: Comparative neurology of the optic tectum (Vanegas $\mathrm{H}$, ed), pp 775-818. New York: Plenum.

Cleland BG, Dubin MW, Levick, WR (1971) Sustained and transient neurons in the cat's retina and lateral geniculate nucleus. J Physiol (Lond) 217:473-496.

Coffey PJ, Lund RD, Rawlins JNP (1989) Retinal transplant-mediated learning in a conditioned suppression task in rats. Proc Natl Acad Sci USA 86:7248-7249.

Collins WF, Mendell LM, Munson JB (1986) On the specificity of sensory reinnervation of cat skeletal muscle. J Physiol (Lond) 375: 587-609.

Dick TE, Viana F, Berger AJ (1988) Electrophysiological determination of the axonal projections of single dorsal respiratory group neurons to the cervical spinal cord of cat. Brain Res 454:31-39.

Finlay BL, Schneps SE, Wilson KG, Schneider GE (1978) Topography of visual and somatosensory projections to the superior colliculus of the golden hamster. Brain Res 142:223-235.

Grasse KL, Douglas RM, Mendelson JR (1993) Alterations in visual receptive fields in the superior colliculus induced by amphetamine. Exp Brain Res 92:453-466.

Hamos JE, Van Horn SC, Raczkowski D, Sherman SM (1987) Synaptic circuit involving an individual retinogeniculate axon in the cat. J Comp Neurol 259:165-192.

Hanker JS, Yates PE, Metz CB, Rustioni A (1977) A new specific, sensitive and non-carcinogenic reagent for the demonstration of horseradish peroxidase. J Histochem 9:789-792.

Hubbard JI (1963) Repetitive stimulation at the mammalian neuromuscular junction, and the mobilization of transmitter. J Physiol (Lond) 169:641-662.

Huerta MF, Harting JK (1984) The mammalian superior colliculus: studies of its morphology and connections. In: Comparative neurology of the optic tectum (Vanegas H, ed), pp 687-773. New York: Plenum.

Iwamoto Y, Kitama T, Yoshida K (1990) Vertical eye movementrelated secondary vestibular neurons ascending in medial longitudinal fasciculus in cat. II. Direct connections with extraocular motoneurons. J Neurophysiol 63:918-935.

Keirstead SA, Vidal-Sanz M, Rasminsky M, Aguayo AJ, Levesque M, So K-F (1985) Responses to light of retinal neurons regenerating axons into peripheral nerve grafts in the rat. Brain Res 359:402-406.

Keirstead SA, Rasminsky M, Fukuda Y, Carter DA, Aguayo AJ, VidalSanz M (1989) Electrophysiological responses in hamster superior colliculus evoked by regenerating retinal axons. Science 246:255-258.

Kirkwood PA, Schmid K, Otto M, Sears TA (1991) Focal blockade of single unit synaptic transmission by iontophoresis of antagonists. Neuroreport 2:185-188.

Kirkwood PA, Schmid K, Sears TA (1993) Functional identities of thoracic respiratory interneurones in the cat. J Physiol (Lond) 461: $667-687$.

Klassen H, Lund RD (1987) Rctinal transplants can drive a pupillary reflex in host rat brains. Proc Natl Acad Sci USA 84:6958-6960.

Klassen H, Lund RD (1990) Retinal graft-mediated pupillary responses in rats: restoration of a reflex function in the mature mammalian brain. J Neurosci 10:578-587.

Lund RD, Radel JD, Coffey PJ (1991) The impact of intracerebral retinal transplants on types of behavior exhibited by host rats. Trends Neurosci 14:358-362.

Mallart A, Martin AR (1967) An analysis of facilitation of transmitter release at the neuromuscular junction of the frog. J Physiol (Lond) 193:679-694.

Mastronarde DN (1987) Two classes of single-input X-cells in cat lateral geniculate nucleus. II. Retinal inputs and the generation of receptive field properties. J Neurophysiol 57:381-413.

Mendell LM, Henneman E (1971) Terminals of single Ia fibers: location, density and distribution within a pool of 300 homonymous motoneurons. J Neurophysiol 34:171-187.

Mooney RD, Rhoades RW (1990) Relationships between physiological and morphological properties of retinocollicular axons in the hamster. J Neurosci 10:3164-3177.

Mooney RD, Klein BG, Rhoades RW (1985) Correlation between the structural and functional characteristics of neurons in the superficial laminae and the hamster's superior colliculus. J Neurosci 5:29893009.

Munson JB, Sypert GW (1979) Properties of single central Ia afferent fibres projecting to motoneurones. J Physiol (Lond) 296:315-327.

Nagano K, Li Q-L, Tamada A, Matsumoto N (1988) An analysis of postsynaptic potentials of tectal neurons of the frog: correlation with impulses recorded from the terminals of retinotectal affercnts. Exp Brain Res 70:429-432.

Nicoll RA, Alger BE (1979) Presynaptic inhibition: transmitter and ionic mechanisms. Int Rev Neurobiol 21:217-258.

Partridge LD, Brown JE (1970) Receptive fields of rat retinal ganglion cells. Vision Res 10:455-460.

Sachs GM, Schneider GE (1984) The morphology of optic tract axons arborizing in the superior colliculus of the hamster. J Comp Neurol 230:155-167.

Sasaki H, Inoue T, Iso H, Fukuda Y, Hayashi Y (1993) Light-dark discrimination after sciatic nerve transplantation to the sectioned optic nerve in adult hamsters. Vision Res 33:877-880.

Schmid K, Kirkwood PA, Munson JB, Shen E, Sears TA (1993) Contralateral projections of thoracic respiratory interneurones in the cat. J Physiol (Lond) 461:647-665.

Simon DK and O'Leary DDM (1991) Relationship of retinotopic 
ordering of axons in the optic pathway to the formation of visual maps in central targets. J Comp Neurol 307:393-404.

Simons DJ, Lund RD (1985) Fetal retinae transplanted over tecta of neonatal rats respond to light and evoke patterned neuronal discharges in the host superior colliculus. Dev Brain Res 21:156-159.

Taylor A, Stephens JA, Somjen G, Appenteng K, O'Donovan MJ (1978) Extracellular spike triggered averaging for plotting synaptic projections. Brain Res 140:344-348.

Thanos S (1992) Adult retinofugal axons regenerating through peripheral nerve grafts can restore the light-induced pupilloconstriction reflex. Eur J Neurosci 4:691-699.

Tiao Y-C, Blakemore C (1976a) Regional specialization in the golden hamster's retina. J Comp Neurol 168:439-458.
Tiao Y-C, Blakemore C (1976b) Functional organization in the superior colliculus of the golden hamster. J Comp Neurol 168:483-504.

Vidal-Sanz M, Bray GM, Villegas-Pérez M-P, Aguayo AJ (1987) Axonal regeneration and synapse formation in the superior colliculus by retinal ganglion cells in the adult rat. J Neurosci 7:2894-2907.

Vidal-Sanz M, Bray GM, Aguayo AJ (1991) Regenerated synapses persist in the superior colliculus after the regrowth of retinal ganglion cell axons. J Neurocytol 20:940-952.

Witpaard J, ter Keurs HEDJ (1975) A reclassification of retinal ganglion cells in the frog, based on tectal endings and response properties. Vision Res 15:1333-1338.

Zhang SJ, Jackson MB (1993) GABA-activated chloride channels in secretory nerve endings. Science 259:531-534. 